\title{
Fixed-dose combinations in type 2 diabetes - role of the canagliflozin metformin combination
}

This article was published in the following Dove Press journal:

Diabetes, Metabolic Syndrome and Obesity: Targets and Therapy

25 June 2015

Number of times this article has been viewed

\section{Joshua W Fleming \\ Laurie W Fleming \\ Courtney S Davis}

Department of Pharmacy Practice, The University of Mississippi School of Pharmacy, Jackson, MS, USA
Correspondence: Joshua W Fleming Department of Pharmacy Practice, The University of Mississippi School of Pharmacy, 2500 North State Street Jackson, MS 39216, USA

Tel + I 6018150604

Fax + $60 \mid 984275$ I

Email jfleming2@umc.edu

\begin{abstract}
Canagliflozin-metformin is one of the newest combination therapies available for the treatment of type 2 diabetes mellitus (T2DM). Canagliflozin is an inhibitor of the sodium-glucose co-transporter 2 which causes an increase in the urinary excretion of glucose. In the present article, we review the safety and efficacy of canagliflozin and metformin from data obtained from Phase III metformin add-on therapy clinical trials as there are no studies to date that specifically evaluate the combination of metformin and canagliflozin. Trials included in this review were dual-therapy trials of subjects who were already taking background metformin and were assigned to receive canagliflozin, glimepiride, or sitagliptin. The addition of canagliflozin to metformin resulted in a decrease in $\mathrm{HbA}_{1 \mathrm{c}}$ of $0.73 \%-0.93 \%$. Canagliflozin $100 \mathrm{mg}$ was considered to be non-inferior to glimepiride and sitagliptin $100 \mathrm{mg}$ with the canagliflozin $300 \mathrm{mg}$ dose being statistically superior to sitagliptin and glimepiride. Other advantages of the use of canagliflozin are reduction in weight $(3.3-4.0 \mathrm{~kg})$ and systolic blood pressure $(3.3-4.7 \mathrm{mmHg})$. The primary disadvantages are potential genital mycotic infections, hypotension, and gastrointestinal side effects from metformin. All things considered, this combination appears to be safe and effective in clinical trials and represents a promising option for the treatment of T2DM.
\end{abstract}

Keywords: type 2 diabetes, fixed-dose combination (FDC), canagliflozin metformin

\section{Introduction to the developments and management issues in type 2 diabetes}

The increasing prevalence of diabetes is a global health concern. Worldwide, it is estimated that 347 million people have diabetes. ${ }^{1}$ Type 2 diabetes mellitus (T2DM) accounts for $90 \%-95 \%$ of cases of diabetes diagnosed in adults and is associated with increased risk of stroke, heart disease, kidney failure, blindness, non-traumatic lowerlimb amputations, and premature death. In the US alone, approximately 29.1 million people (9.3\% of the population) have diabetes with total medical costs estimated to be $\$ 245$ billion in 2012. Health care expenditures for patients with diabetes are estimated to be 2.3 times higher compared to those without diabetes. ${ }^{2}$

Glycemic control is necessary to slow the progression of microvascular and macrovascular complications. ${ }^{1}$ The multifaceted pathology of the disease complicates its management. ${ }^{3}$ The pathogenesis of diabetes includes $\beta$-cell dysfunction, impaired tissue glucose utilization, and increased hepatic glucose and free fatty acid production. Genetic predisposition may increase the likelihood of developing T2DM, but environmental factors, including obesity, sedentary lifestyles, and age, increase the risk of developing insulin resistance. ${ }^{4}$ 
Due to the complexity of the disease, many patients with T2DM require multiple oral anti-hyperglycemic agents (AHAs) and even insulin therapy to maintain adequate blood glucose control. In addition, patients often require treatment for both dyslipidemia and hypertension. ${ }^{4}$ A US survey of 875 adults with diabetes aged $\geq 50$ years found that $50 \%$ of respondents were using greater than or equal to seven medications, including greater than or equal to two AHAs. ${ }^{5}$ Most studies report a $65 \%-85 \%$ adherence rate to oral AHA, although rates can be lower (36\%-54\%) for regimens requiring more frequent dosing. ${ }^{6} \mathrm{~A}$ large, longitudinal study of medical claims data from a US managed-care company over a 3-year period found that improved adherence to diabetes medications was associated with $13 \%$ less risk of subsequent hospitalizations or emergency department visits and decreased medical costs. ${ }^{7}$

\section{History, development, and rationale for increasing use of fixed-dose combinations in diabetes}

Combination products can simplify treatment regimens for patients, which is especially important for patients with diabetes on multiple medications. A meta-analysis of nine studies consisting of patients with chronic disease states, inclusive of diabetes and hypertension, was conducted to compare medication compliance with fixed-dose combination (FDC) vs free-drug component regimens. A 26\% relative risk (RR) reduction in noncompliance was seen in the FDC group (RR 0.74; 95\% confidence interval, 0.69-0.80). ${ }^{8}$ Another analysis with T2DM patients taking either FDC or a combination of single pills showed increased compliance, improved satisfaction, and lower direct medical costs in patients receiving the FDC. ${ }^{9}$

The first FDC for the treatment of diabetes, Glucovance ${ }^{\circledR}$ (glyburide, metformin), combining a sulfonylurea and a biguanide, was approved by the US Food and Drug Administration (FDA) in the early 2000s, and novel combinations have since evolved..$^{10} \mathrm{FDC}$ products currently approved for the treatment of T2DM with complementary therapeutic approaches to lowering blood glucose include sulfonylurea/ metformin, secretagogue/metformin, thiazolidinedione/ metformin, thiazolidinedione/sulfonylurea, dipeptidyl peptidase-4 (DPP-4) inhibitor/metformin, and most recently, sodium-glucose co-transporter 2 (SGLT-2) inhibitor/metformin combinations. ${ }^{11}$ In August 2014, the FDA approved Invokamet ${ }^{\circledR}$, an FDC of canagliflozin and metformin, which is the focus of this review. ${ }^{12}$

\section{Pharmacology}

This FDC combines the actions of canagliflozin and metformin..$^{13}$ Canagliflozin exhibits its effects on glucose control through altering reabsorption of glucose in the kidney. ${ }^{13-15}$ The primary action of the kidney is to reabsorb all glucose back into circulation up to a threshold of approximately $180 \mathrm{mg} / \mathrm{dL}$. Beyond that threshold, the kidneys excrete glucose into the urine. The sodium-glucose co-transporter 1 (SGLT-1) and SGLT-2 are proteins located in the proximal renal tubule. These proteins are responsible for the reabsorption of glucose. SGLT-1 accounts for approximately $10 \%$ of the reabsorbed glucose, and SGLT-2 accounts for the remaining 90\%. ${ }^{14,15}$ Canagliflozin inhibits SGLT-2 which leads to a decrease in the reabsorption threshold to approximately $60 \mathrm{mg} / \mathrm{dL}$ and an increase in the urinary glucose excretion. ${ }^{15} \mathrm{~A}$ dose-dependent reduction in plasma glucose occurs within the first day of dosing. ${ }^{13}$ Metformin is known to decrease hepatic glucose production and improve insulin sensitivity by increasing glucose uptake in the peripheral tissues. ${ }^{13}$

\section{Bioequivalence}

Six studies were performed to compare the bioequivalence of immediate-release FDC tablets containing canagliflozin and metformin with the concomitant administration of the single components of canagliflozin and metformin in healthy-fed adults. Across all dose levels, when dosed either as FDC or individual components, the pharmacokinetics of canagliflozin and metformin was found to be bioequivalent and well tolerated. ${ }^{16}$

\section{Absorption}

Canagliflozin dosing results in a mean absolute oral bioavailability of approximately $65 \%$. When metformin is given under fasting conditions, its absolute bioavailability is $50 \%-60 \% .^{13}$

\section{Distribution}

The mean steady-state volume of distribution for canagliflozin is $119 \mathrm{~L}$, which indicates extensive tissue distribution. Canagliflozin is $99 \%$ bound to plasma proteins, primarily albumin. Steady-state concentrations are reached after 4-5 days of once-daily dosing. For metformin, after a single dose of metformin $850 \mathrm{mg}$, the volume of distribution averages $654 \pm 358 \mathrm{~L}$. It is negligibly bound to plasma proteins. Steady-state concentrations are reached within 24-48 hours of usual clinical doses. ${ }^{13}$ 


\section{Metabolism}

Canagliflozin is metabolized predominantly by $O$-glucuronidation. Metformin is excreted unchanged in the urine. ${ }^{13}$

\section{Excretion}

Canagliflozin is excreted primarily via the fecal and renal routes. The terminal half-life is 10.6 hours and 13.1 hours for the $100 \mathrm{mg}$ and $300 \mathrm{mg}$ doses, respectively. Metformin is primarily eliminated via the renal route through tubular secretion, with a plasma elimination half-life of 6.2 hours. ${ }^{13}$

\section{Efficacy Monotherapy}

Canagliflozin as a single agent has had limited trial data, and this is largely represented by one 26-week, randomized, placebo-controlled trial. In this trial, subjects were not allowed to take any other AHA, and the primary endpoint was change in $\mathrm{HbA}_{1 \mathrm{c}}$ from baseline to week 26 . Other outcomes that were assessed were proportion of subjects achieving an $\mathrm{HbA}_{1 \mathrm{c}}$ of $<7 \%$, changes from baseline in fasting plasma glucose (FPG) and systolic blood pressure (SBP), and percent change from baseline in body weight high-density lipoprotein (HDL) and triglycerides. There were 584 subjects included in the trial with a mean age of 55.4 years and a relatively equal distribution of males and females. Approximately $68 \%$ of the subjects enrolled were white followed by $14.7 \%$ Asian, $7 \%$ black or African American, and 8.6\% American Indian, Alaska Native, or other. Subjects in the main study had been diagnosed with diabetes for 4.6 years and had a mean $\mathrm{HbA}_{1 \mathrm{c}}$ of $8 \%$ with a body mass index (BMI) of $31.6 \mathrm{~kg} / \mathrm{m}^{2}$, and approximately half of those subjects had been on other AHA prior to enrollment. This trial also included a sub-study of subjects with an $\mathrm{HbA}_{1 \mathrm{c}}$ over $10 \%$. This high-glycemic sub-study included 91 subjects with relatively similar characteristics to the subjects enrolled in the main study. In the high-glycemic group, the mean age was slightly younger at 49.3 years, the mean $\mathrm{HbA}_{1 \mathrm{c}}$ was $10.6 \%$, the mean BMI was $30.5 \mathrm{~kg} / \mathrm{m}^{2}$, duration of diabetes was 4.9 years, and only $23.1 \%$ had been on previous AHA prior to enrollment. ${ }^{17}$

Subjects enrolled in the main study achieved a $0.77 \%$ and $1.03 \%$ reduction in $\mathrm{HbA}_{1 \mathrm{c}}$ at week 26 in the canagliflozin $100 \mathrm{mg}$ and canagliflozin $300 \mathrm{mg}$ groups, respectively. These results represented a significant reduction in $\mathrm{HbA}_{1 \mathrm{c}}$ over the placebo group which resulted in a $0.14 \%$ increase in $\mathrm{HbA}_{1 \mathrm{c}}$. A significantly greater proportion of subjects on canagliflozin $100 \mathrm{mg}$ (44.5\%) and canagliflozin $300 \mathrm{mg}$ (62.4\%) achieved a $\mathrm{HbA}_{1 \mathrm{c}}$ of $<7 \%$ when compared to placebo (20.6\%). FPG levels were significantly reduced in the canagliflozin $100 \mathrm{mg}$ $(-1.5 \mathrm{mmol} / \mathrm{L})$ and canagliflozin $300 \mathrm{mg}(-1.9 \mathrm{mmol} / \mathrm{L})$ over that in the placebo group $(0.5 \mathrm{mmol} / \mathrm{L})$. An even greater reduction in postprandial glucose (PPG) was seen in both the canagliflozin $100 \mathrm{mg}(-2.4 \mathrm{mmol} / \mathrm{L})$ and canagliflozin $300 \mathrm{mg}(-3.3 \mathrm{mmol} / \mathrm{L})$. The high-glycemic sub-study achieved a $2.8 \%$ and $3.9 \%$ reduction in $\mathrm{HbA}_{1 \mathrm{c}}$ in canagliflozin $100 \mathrm{mg}$ and canagliflozin $300 \mathrm{mg}$ groups, respectively, and an approximate $5 \mathrm{mmol} / \mathrm{L}$ reduction in $\mathrm{FPG}$ and $7 \mathrm{mmol} / \mathrm{L}$ reduction in PPG. ${ }^{17}$

Canagliflozin-treated subjects also achieved a modest but statistically significant decrease in weight over the course of 26 weeks with a mean loss of $3.4 \mathrm{~kg}$ in the high-dose canagliflozin group. In addition to a modest weight loss, subjects receiving $100 \mathrm{mg}$ and $300 \mathrm{mg}$ of canagliflozin achieved a $3.7 \mathrm{mmHg}$ and $5.4 \mathrm{mmHg}$ reduction in SBP, respectively. Finally, treatment with canagliflozin was associated with an approximate $6 \%$ increase in HDL over the 26 -week trial. The high-glycemic subgroup achieved similar results for weight loss, decrease in SBP, and increase in HDL. ${ }^{17}$

Metformin use as a single agent has been well studied, and the clinical benefits are known by mostly all clinicians. In a historical trial of metformin monotherapy, subjects with non-insulin-dependent diabetes were enrolled to evaluate the efficacy of metformin. At baseline, these subjects were similar to the subjects enrolled in the canagliflozin monotherapy trial, except that the duration of diabetes was slightly longer at 6 years. The baseline $\mathrm{HbA}_{\mathrm{lc}}$ was very similar at $8.2 \%$. After 29 weeks, subjects achieved a statistically significant reduction in $\mathrm{HbA}_{1 \mathrm{c}}$ by $1.4 \%$, and a reduction in FPG by $2.9 \mathrm{mmol} / \mathrm{L}$. Subjects also saw a modest weight loss of $0.6 \mathrm{~kg}$, but this was not statistically significant when compared to placebo. ${ }^{18}$

\section{Comparative data}

To date, there are no clinical trials that involve direct comparisons of subjects taking the combination canagliflozinmetformin. In this review, we focus on trials directly comparing canagliflozin to other therapies in subjects who are on background metformin. Comparisons available include glimepiride and sitagliptin, each of which represents an equally viable addition to metformin therapy. ${ }^{19-21}$

One of the most traditional secondary therapies in type 2 diabetes is the sulfonylurea class. In CANTATA-SU, the addition of canagliflozin was compared to the addition of glimepiride to background metformin in a Phase III, doubleblind, randomized, active control, non-inferiority trial. In this 
52-week trial, subjects were randomized in a 1:1:1 fashion to receive canagliflozin $100 \mathrm{mg}$, canagliflozin $300 \mathrm{mg}$, or glimepiride which was titrated to a maximum dose of $6 \mathrm{mg}$ or $8 \mathrm{mg}$ (mean maximum dose was $5.6 \mathrm{mg}$ ) based on the maximum approved dose in the study location. All subjects enrolled were required to be on a stable metformin dose of at least $1,500 \mathrm{mg}$ or greater with an $\mathrm{HbA}_{1 \mathrm{c}}$ of $7 \%-9.5 \%$. Subjects were not eligible if they had an estimated glomerular filtration rate (eGFR) of less than $55 \mathrm{~mL} / \mathrm{min} / 1.73 \mathrm{~m}^{2}$ (or less than $60 \mathrm{~mL} / \mathrm{min} / 1.73 \mathrm{~m}^{2}$ based on the restrictions for metformin at the study center). Additionally, they were required to have a serum creatinine of less than $124 \mu \mathrm{mol} / \mathrm{L}$ for men and less than $115 \mu \mathrm{mol} / \mathrm{L}$ for women. Lastly, subjects with a history of more than one episode of severe hypoglycemia within 6 months prior to enrollment were not allowed to enter the trial. ${ }^{19}$

The primary endpoint of this trial was the change in $\mathrm{HbA}_{1 \mathrm{c}}$ from baseline to week 52. Secondary efficacy endpoints included the following: percent change from baseline in body weight; proportion of patients achieving goal $\mathrm{HbA}_{1 \mathrm{c}}$; change in FPG, SBP, and diastolic blood pressure; and percent change in lipid parameters. The primary analysis was based on a modified intent-to-treat population which included all subjects who received at least one dose of study drug with the last observation carried forward. The trial was designed to prove that the addition of canagliflozin to metformin was noninferior to the addition of a sulfonylurea. The pre-specified non-inferiority margin was set at $0.3 \%$. If non-inferiority was shown, superiority was determined if there was a less than $0 \%$ difference when compared to glimepiride. ${ }^{19}$
There were 1,450 subjects enrolled in the trial with equal distribution of subjects across the three groups. The mean age at the time of enrollment was 56 years, and the subjects were predominately white (67\%) followed by Asian (19\%), other (9\%), and black or African American (5\%). At baseline, subjects had been diagnosed with diabetes for approximately 6.6 years and had a mean $\mathrm{HbA}_{1 \mathrm{c}}$ of $7.8 \%$ with a mean FPG of $9.2 \mathrm{mmol} / \mathrm{L}$. The average body weight of subjects enrolled was $86.5 \mathrm{~kg}$ with a BMI of $31 \mathrm{~kg} / \mathrm{m}^{2}{ }^{19}$

In the efficacy analysis, both doses of canagliflozin were proven to be non-inferior to glimepiride, and the canagliflozin $300 \mathrm{mg}$ dose reached the pre-specified superiority margin (Table 1). There was no significant difference in the percentage of patients achieving glycemic goal with approximately $60 \%$ achieving a goal $\mathrm{HbA}_{1 \mathrm{c}}$ of $<7 \%$ and $30 \%$ achieving a goal of $<6.5 \%$ across all three groups. Maximum $\mathrm{HbA}_{1 \mathrm{c}}$ benefits were seen with all three groups by week 26 . These results were maintained in both of the canagliflozin groups through week 52, but the $\mathrm{HbA}_{1 \mathrm{c}}$ had an upward trend from week 26 to week 52 in the glimepiride group. There was a numerically greater (approaching statistically significant) reduction in FPG in both of the canagliflozin groups as compared to glimepiride. ${ }^{19}$

Significant reductions in weight were seen in both of the canagliflozin arms with subjects in the $100 \mathrm{mg}$ group seeing a $4.2 \%$ reduction in body weight and patients in the $300 \mathrm{mg}$ group seeing a $4.7 \%$ reduction, while the glimepiride group saw a $1 \%$ increase in body weight. Subjects receiving canagliflozin $100 \mathrm{mg}$ and $300 \mathrm{mg}$ saw a modest but clinically

Table I Comparison of efficacy endpoints

\begin{tabular}{|c|c|c|c|c|c|c|c|}
\hline \multirow[t]{2}{*}{ Study } & \multirow[t]{2}{*}{ Design } & \multirow{2}{*}{$\begin{array}{l}\text { Subjects } \\
\text { (n) }\end{array}$} & \multirow{2}{*}{$\begin{array}{l}\text { Duration } \\
\text { (weeks) }\end{array}$} & \multirow[t]{2}{*}{ Outcomes } & \multicolumn{3}{|l|}{ Results } \\
\hline & & & & & Cana $100 \mathrm{mg}$ & Cana $300 \mathrm{mg}$ & Placebo \\
\hline \multirow[t]{5}{*}{ Cana Mono ${ }^{17}$} & $R C, D B, P C$ & 584 & 26 & $\mathrm{HbA}_{\mathrm{Ic}}(\%)$ & $-0.77^{\mathrm{a}}$ & $-1.03^{\mathrm{a}}$ & 0.14 \\
\hline & & & & $\mathrm{FPG}(\mathrm{mmol} / \mathrm{L})$ & $-1.5^{\mathrm{a}}$ & $-1.9^{a}$ & 0.5 \\
\hline & & & & Weight (kg) & $-2.5^{a}$ & $-3.4^{\mathrm{a}}$ & -0.5 \\
\hline & & & & $\mathrm{SBP}(\mathrm{mmHg})$ & -3.7 & -5.4 & 0.4 \\
\hline & & & & & Cana $100 \mathrm{mg}$ & Cana $300 \mathrm{mg}$ & Glimepiride \\
\hline \multirow[t]{5}{*}{ Cana vs SU ${ }^{18}$} & $\mathrm{RC}, \mathrm{DB}, \mathrm{AC}, \mathrm{NI}$ & $\mathrm{I}, 450$ & 52 & $\mathrm{HbA}_{\mathrm{Ic}}(\%)$ & -0.82 & $-0.93^{b}$ & -0.81 \\
\hline & & & & $\mathrm{FPG}(\mathrm{mmol} / \mathrm{L})$ & -1.35 & -1.52 & -1.02 \\
\hline & & & & Weight (kg) & $-3.7^{c}$ & $-4.0^{c}$ & 0.7 \\
\hline & & & & $\mathrm{SBP}(\mathrm{mmHg})$ & $-3.3^{c}$ & $-4.8^{c}$ & 0.2 \\
\hline & & & & & Cana $100 \mathrm{mg}$ & Cana $300 \mathrm{mg}$ & Sita $100 \mathrm{mg}$ \\
\hline \multirow[t]{4}{*}{ Cana vs Sita ${ }^{19}$} & $\mathrm{RC}, \mathrm{DB}, \mathrm{AC}, \mathrm{PG}, \mathrm{NI}$ & 1,284 & 52 & $\mathrm{HbA}_{\mathrm{Ic}}(\%)$ & -0.73 & $-0.88^{d}$ & -0.73 \\
\hline & & & & $\mathrm{FPG}(\mathrm{mmol} / \mathrm{L})$ & $-1.5^{\mathrm{d}}$ & $-2.0^{\mathrm{d}}$ & -1.0 \\
\hline & & & & Weight (kg) & $-3.3^{d}$ & $-3.7^{\mathrm{d}}$ & -1.2 \\
\hline & & & & $\mathrm{SBP}(\mathrm{mmHg})$ & $-3.5^{d}$ & $-4.7^{\mathrm{d}}$ & -0.7 \\
\hline
\end{tabular}

Notes: ${ }^{a}<0.05$ when compared to placebo; ${ }^{b}$ met pre-specified superiority margins; ${ }^{c} P<0.05$ when compared to glimepiride; ${ }^{d} P<0.05$ when compared to sitagliptin. Abbreviations: Cana, canagliflozin; Mono, monotherapy; RC, randomized controlled; DB, double-blind; PC, placebo controlled; FPG, fasting plasma glucose; SBP, systolic blood pressure; SU, sulfonylurea; AC, active control; NI, non-inferiority trial; Sita, sitagliptin; PG, parallel crossover group. 
significant reduction in SBP. Finally, there were no clinically significant differences in low-density lipoproteins (LDLs), HDLs, or triglycerides. ${ }^{19}$

The second currently available trial is designed to evaluate the efficacy of canagliflozin as compared to placebo and sitagliptin in patients on metformin monotherapy. This 52-week trial included 1,284 subjects and randomized patients to canagliflozin $100 \mathrm{mg}$, canagliflozin $300 \mathrm{mg}$, sitagliptin $100 \mathrm{mg}$, or placebo in a 2:2:2:1 fashion. The trial was conducted in two periods. The first period lasted 26 weeks and included all four treatment arms. At the end of period one, all patients who were receiving a placebo were transitioned to sitagliptin $100 \mathrm{mg}$ for another 26 weeks. This allowed for a randomized, double-blind, placebo and active control period and a double-blind active control period. All subjects who were randomized to canagliflozin $100 \mathrm{mg}$, canagliflozin $300 \mathrm{mg}$, and sitagliptin $100 \mathrm{mg}$ in period one continued with their current treatment during period two. Similar to the sulfonylurea trial, subjects were required to be on a stable dose of metformin of at least $1,500 \mathrm{mg}$ or more with an $\mathrm{HbA}_{1 \mathrm{c}}$ greater than 7\%. FPG of subjects could not be $>15 \mathrm{mmol} / \mathrm{L}$ or $<6.1 \mathrm{mmol} / \mathrm{L}$ at the end of the run-in period. Notable exclusion criteria included history of cardiovascular disease, uncontrolled hypertension, eGFR of less than $55 \mathrm{~mL} / \mathrm{min} / 1.73 \mathrm{~m}^{2}$ (or $<60 \mathrm{~mL} / \mathrm{min} / 1.73 \mathrm{~m}^{2}$ based on study center metformin labeling), or serum creatinine greater than $124 \mu \mathrm{mol} / \mathrm{L}$ for men and greater than $115 \mu \mathrm{mol} / \mathrm{L}$ for women. ${ }^{20}$

The primary endpoint of this trial was the change in $\mathrm{HbA}_{1 \mathrm{c}}$ from baseline to week 26 (period one). The change in $\mathrm{HbA}_{1 \mathrm{c}}$ from baseline to week 56 was a key secondary outcome. Other outcomes that were measured at week 26 were the following: proportion of patients reaching goal $\mathrm{HbA}_{1 \mathrm{c}}$; change in FPG, PPG, and SBP; and percent change in body weight, triglycerides, and HDL. Outcome measures at week 52 included the following: change in FPG and SBP; and percent change in body weight, triglycerides, and HDL. Primary efficacy analyses were conducted on a modified intent-to-treat population which included all subjects who received at least one dose of the study drug using a lastobservation-carried-forward approach. The authors' prespecified non-inferiority margin for $\mathrm{HbA}_{1 \mathrm{c}}$ was set at $0.3 \%$ for the upper limit of the two-sided confidence interval as compared to sitagliptin. The pre-specified superiority margin for $\mathrm{HbA}_{1 \mathrm{c}}$ was set at less than $0 \%$ based on the upper bound of the confidence interval. ${ }^{20}$

Subjects included in this trial had a mean age of 55 years at baseline and had had a diagnosis of type 2 diabetes for approximately 7 years with a mean $\mathrm{HbA}_{1 \mathrm{c}}$ of $8 \%$. The approximate mean FPG was $9.2 \mathrm{mmol} / \mathrm{L}$. There was an equal distribution of males and females with the predominate race being white (70\%) followed by Asian (15\%), other (13\%), and black or African American (4\%). The mean BMI was $32 \mathrm{~kg} / \mathrm{m}^{2}$ with an average body weight of $87 \mathrm{~kg} .{ }^{20}$

Glycemic outcomes at week 26 included a statistically significant reduction over placebo in $\mathrm{HbA}_{1 \mathrm{c}}$ for the canagliflozin $100 \mathrm{mg}(-0.62 \%)$ and canagliflozin $300 \mathrm{mg}(-0.77 \%)$. No statistical analysis was performed for the sitagliptin group, but the $\mathrm{HbA}_{1 \mathrm{c}}$ lowering was comparable at $-0.66 \%$. By week 26 , the canagliflozin $100 \mathrm{mg}(44.5 \%)$ and $300 \mathrm{mg}(57.8 \%)$ groups had a significantly greater number of subjects achieving an $\mathrm{HbA}_{1 \mathrm{c}}$ of less than $7 \%$ when compared to placebo. Of the sitagliptin group, $54.5 \%$ achieved an $\mathrm{HbA}_{1 \mathrm{c}}$ of less than $7 \%$. At week 52 , both doses of canagliflozin had achieved non-inferiority to sitagliptin $100 \mathrm{mg}$, and canagliflozin $300 \mathrm{mg}$ had achieved statistical superiority to sitagliptin $100 \mathrm{mg}$ (Table 1). Slightly over half of the subjects randomized to canagliflozin $300 \mathrm{mg}$ and sitagliptin $100 \mathrm{mg}$ achieved an $\mathrm{HbA}_{1 \mathrm{c}}$ of less than $7 \%$ compared to approximately $40 \%$ in the canagliflozin $100 \mathrm{mg}$ group. Only about one-quarter of all subjects in all three groups achieved an $\mathrm{HbA}_{1 \mathrm{c}}$ of less than $6.5 \%$. Both canagliflozin groups had statistically greater reductions in FPG as compared to sitagliptin with the greatest reduction seen at week 26 (Table 1 ). ${ }^{20}$

In terms of the metabolic parameters, we focus on the week 52 endpoints. Both doses of canagliflozin were associated with a statistically significant body weight reduction over sitagliptin with the majority of weight loss seen by week 34 (Table 1). Statistically and clinically significant reductions in SBP were seen in both canagliflozin groups when compared to sitagliptin (Table 1). As with the sulfonylurea trial, there were no statistically significant differences in triglycerides, HDL, or LDL. ${ }^{20}$

A Phase II trial evaluated twice-daily treatment with canagliflozin, either $50 \mathrm{mg}$ or $150 \mathrm{mg}$ twice daily as an add-on therapy to metformin. This trial closely mimicked how the commercial combination product is dosed. There were 279 patients randomized to $50 \mathrm{mg}, 150 \mathrm{mg}$, or placebo twice daily for 18 weeks after a run-in period with metformin. Overall glycemic efficacy and safety findings were similar compared to other trials discussed. Reductions in $\mathrm{HbA}_{1 \mathrm{c}}$ were slightly lower than reductions seen in Phase III trials. This study lasted 18 weeks, and approximately $25 \%$ of patients at baseline had an $\mathrm{HbA}_{1 \mathrm{c}}<7 \%$ which could account for the slightly lower $\mathrm{HbA}_{1 \mathrm{c}}$ reduction of $-0.44 \%$ and $-0.60 \%$ in the $50 \mathrm{mg}$ and $150 \mathrm{mg}$ group, respectively. ${ }^{22}$ 


\section{Safety and tolerability}

Data were pooled from four 26-week placebo-controlled trials, one in which canagliflozin was used as monotherapy and three in which canagliflozin was used as an add-on therapy with metformin (with or without additional agents). During these trials, 1,667 patients were exposed to canagliflozin, and 1,275 patients were exposed to a combination of canagliflozin and metformin. The most commonly reported adverse events $(>2 \%)$ for patients treated with canagliflozin were genital mycotic infections, urinary tract infections, increased urination, vulvovaginal pruritus, thirst, constipation, and nausea. Using data pooled from eight placebo- and active-controlled trials of 6,177 patients exposed to canagliflozin, in addition to the side effects listed above, fatigue and hypersensitivity reactions were also reported in $>2 \%$ of patients. ${ }^{13}$

Volume depletion-related adverse events, including hypotension, postural dizziness, orthostatic hypotension, syncope, and dehydration, occurred more commonly in patients on the $300 \mathrm{mg}$ dosage of canagliflozin and those on concomitant loop diuretics, those with moderate renal impairment (eGFR $30 \mathrm{~mL} / \mathrm{min} / 1.73 \mathrm{~m}^{2}$ to less than $60 \mathrm{~mL} / \mathrm{min} / 1.73 \mathrm{~m}^{2}$ ), or those aged 75 years and older. Caution should also be used in patients taking medications that interfere with the reninangiotensin-aldosterone system or those with a low SBP. ${ }^{13}$

Data pooled from four placebo-controlled trials and a moderate renal impairment trial demonstrated a dose-dependent increase in serum creatinine in patients treated with canagliflozin. The dose of canagliflozin should be limited to $50 \mathrm{mg}$ twice daily in patients with moderate renal impairment (eGFR $45 \mathrm{~mL} / \mathrm{min} / 1.73 \mathrm{~m}^{2}$ to less than $60 \mathrm{~mL} / \mathrm{min} / 1.73 \mathrm{~m}^{2}$ ). Hypoglycemia is more likely to occur when canagliflozin is used in combination with sulfonylureas or insulin therapy; therefore, a lower dose of these agents may be required. Dose-related increases in serum magnesium, serum potassium, LDL-cholesterol, and nonHDL-cholesterol have also occurred in placebo-controlled trials with canagliflozin. These laboratory parameters should be monitored. ${ }^{13}$

The most common adverse events associated with metformin include diarrhea, nausea, vomiting, flatulence, asthenia, abdominal discomfort, and headache. The dose should be gradually escalated to decrease the risk of gastrointestinal side effects. In the long term, metformin has been associated with vitamin $B_{12}$ deficiency, and its levels should be monitored annually. ${ }^{13}$

Lactic acidosis can occur in the event of metformin accumulation. Patients with renal impairment, sepsis, dehydration, excess alcohol intake, hepatic impairment, and acute congestive heart failure have an increased risk. Metformin should not be used when the serum creatinine level is greater than or equal to $114.4 \mu \mathrm{mol} / \mathrm{L}$ in men or $106.8 \mu \mathrm{mol} / \mathrm{L}$ in women. Metformin should be temporarily discontinued at the time of or prior to radiologic studies and held for at least 48 hours and until renal function is determined to be normal. It should also be held for surgical procedures requiring food and fluid restrictions until oral intake is resumed and renal function is found to be normal. ${ }^{13}$

\section{Patient-focused perspectives}

Patients' acceptance of a treatment regimen is an important factor to consider when choosing the most appropriate therapy. The patient must buy-in to the regimen in order for it to be effective. Even the best treatment will not work if the patient is not willing to take it, stops taking it, or does not take it as instructed. One study administered a validated questionnaire to patients with type 2 diabetes in an outpatient clinic in Jordan. This included a self-reported medication adherence scale (Morisky Scale), diabetes knowledge questionnaire (ADKnowl Questionnaire), and health-related quality of life (HRQoL) scale (EQ-5D Questionnaire). Patients were about nine times less likely to adhere to diabetes medications if they received more than one dose of medication per day, and the odds of adherence was inversely related to the number of medications prescribed; therefore, simplifying regimens, like using an FDC, can be beneficial. ${ }^{23}$

Side effects are a major factor that can affect adherence..$^{23}$ While side effects are not benign, as discussed previously, the canagliflozin metformin combination was generally well tolerated in the Phase III study of canagliflozin vs placebo and sitagliptin in patients on background metformin with slightly less serious adverse events reported in the canagliflozin groups (100 mg and $300 \mathrm{mg}$ ) compared to the combination with sitagliptin $(4.1 \%, 3.3 \%$, and $4.9 \%$, respectively). ${ }^{20}$ There are also several side effects that may be advantageous for patients. Weight loss, reduced blood pressure, and increased HDL-cholesterol are associated with the canagliflozin and metformin combination. ${ }^{20}$ With the numerous diabetes medications that are associated with weight gain, patients already struggling with obesity may find this discouraging as it can make it more difficult for them to meet their weight loss goals. The combination of a weight neutral medication, metformin, and a medication that has the potential for weight loss, canagliflozin, may appeal to these patients specifically. ${ }^{17}$

Hypoglycemia, another side effect of many diabetes medications, has the potential to affect many aspects of patients' 
lives such as quality of life, work productivity, and medication adherence. One study assessed hypoglycemia as related to the patient's perspective. Out of 6,065 patients treated with oral or injectable agents for diabetes, $56 \%$ of participants self-reported hypoglycemia, and of those, $29 \%$ experienced hypoglycemia recently. Of the patients who reported recent hypoglycemia, $60.9 \%$ had a low or medium adherence score, while only $39.1 \%$ had a high adherence score (based on Morisky Scale). More patients on diabetes medications with recent hypoglycemia reported interference with social activities in the previous 4 weeks compared to patients who never had hypoglycemia. A greater percentage of patients were absent from work in the recent hypoglycemia group compared to the group who never had hypoglycemia $(7.6 \%$ vs $3.5 \%, P<0.001)$. Also, $25.5 \%$ of patients with recent hypoglycemia indicated work productivity impairment, while only $16.3 \%$ reported this in the group that never had hypoglycemia $(P<0.001)$. The Short Form-36 health survey, version 2, and questions from the US National Health and Wellness Survey were used to assess HRQoL. Overall HRQoL decreased in those who had experienced recent or any past hypoglycemia more so than the group who never reported hypoglycemia. ${ }^{24}$ Given the low incidence of hypoglycemia associated with metformin and canagliflozin in clinical trials, one could extrapolate that this may in turn lead to improved adherence to medications, less interference with social activities, less missed work days, and an overall improvement in HRQoL. ${ }^{24,25}$ As highlighted above, the combination of canagliflozin and metformin has many qualities that may be promising from the patient's perspective.

Canagliflozin-metformin is available in the following strengths: canagliflozin $50 \mathrm{mg} / \mathrm{metformin} 500 \mathrm{mg}$, canagli-

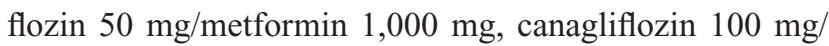
metformin $500 \mathrm{mg}$, and canagliflozin $100 \mathrm{mg} / \mathrm{metformin}$ $1,000 \mathrm{mg}$. The maximum recommended dose for combination is canagliflozin $300 \mathrm{mg}$ and metformin 2,000 mg per day in divided doses. In patients with an eGFR of at least 45-60 $\mathrm{mL} / \mathrm{min} / 1.73 \mathrm{~m}^{2}$, the total dose of canagliflozin should not exceed $100 \mathrm{mg}$ per day in divided doses. Patients should be counseled on taking this medication twice daily with food to decrease the incidence of gastrointestinal side effects seen with metformin. ${ }^{13}$

\section{Place in therapy}

According to the American Diabetes Association (ADA), the initial approach to therapy should be based on patientspecific factors and the baseline $\mathrm{HbA}_{1 \mathrm{c}}$. In addition to lifestyle modifications, metformin monotherapy is considered to be the appropriate initial medication for most patients who are newly diagnosed with T2DM. The ADA goes on to suggest initiating combination therapy in patients who have an $\mathrm{HbA}_{1 \mathrm{c}}$ of at least $9 \%$ with a preference toward combination therapy with insulin in patients with an $\mathrm{HbA}_{1 \mathrm{c}}$ greater than $10 \% .^{21}$ The American Association of Clinical Endocrinologists (AACE) takes a more aggressive approach to management of T2DM and suggests initiating combination therapy in patients with an $\mathrm{HbA}_{1 \mathrm{c}}$ higher than $7.5 \%$ and suggests adding insulin to that combination in patients with an $\mathrm{HbA}_{1 \mathrm{c}}$ greater than $9 \%{ }^{26}$

Given these respected recommendations from ADA and AACE, one must ask where the combination of metformin and canagliflozin should be considered. In an otherwise healthy population, this combination could be considered as an initial therapy in patients with an $\mathrm{HbA}_{1 \mathrm{c}}$ of at least $7.5 \%$ if an aggressive approach is the target. In populations where a less aggressive approach is the target (elderly, multiple comorbid disease states, limited life expectancy, etc), this combination could be considered as an initial treatment option in patients with an $\mathrm{HbA}_{1 \mathrm{c}}$ of at least $9 \%$. Patients on metformin monotherapy who have not reached their goal within 3 months could also be considered for the canagliflozin-metformin combination. At this point, use of canagliflozin-metformin with insulin therapy has not yet been evaluated in clinical trials, and use of this combination should be done with caution.

Given the availability of other combinations with metformin, one must also consider when to use canagliflozinmetformin or one of the other combination agents. One of the key benefits seen in patients treated with canagliflozin that presents a clinical edge is the potential for weight reduction. With most diabetes agents either causing weight gain or being weight neutral, this is one of the few add-ons that could result in a modest weight reduction. Combination canagliflozin-metformin could also present an advantage in patients who have hypertension given its ability to reduce SBP. Use of this agent should be cautioned in patients who have had a significant history of genital mycotic infections, hypotension, or poor renal function.

Overall, the combination of canagliflozin-metformin appears to be a safe and effective option for patients with T2DM with a moderately elevated $\mathrm{HbA}_{1 \mathrm{c}}(7.5 \%-10 \%)$. The potential for reduction in weight and SBP gives this combination an advantage over combinations containing a sulfonylurea or DPP-4 inhibitor, but this must be weighed out with the potential complication of genital mycotic infections and hypotension. Treatment of T2DM continues to evolve, 
and combinations such as canagliflozin-metformin represent a promising option for patients struggling to obtain control of their glucoses.

\section{Disclosure}

No relevant financial disclosures or conflicts of interest to report for any of the above-listed authors.

\section{References}

1. Danaei G, Finucane MM, Lu Y, et al; Global Burden of Metabolic Risk Factors of Chronic Diseases Collaborating Group (Blood Glucose). National, regional, and global trends in fasting plasma glucose and diabetes prevalence since 1980: systematic analysis of health examination surveys and epidemiological studies with 370 country-years and 2.7 million participants. Lancet. 2011;378(9785):31-40.

2. CDC, Department of Health and Human Services [homepage on the Internet]. National diabetes statistics report, 2014. [updated 2014; cited May 15, 2015]. Available from: http://www.cdc.gov//diabetes/ pubs/statsreport14/national-diabetes-report-web.pdf. Accessed September 28, 2014.

3. Stumvoll M, Goldstein BJ, van Haeften TW. Pathogenesis of type 2 diabetes. Endocr Res. 2007;32(1-2):19-37.

4. Kroon LA, Williams C. Diabetes mellitus. In: Alldredge BK, Corelli RL, Ernst ME, et al, editors. Koda-Kimble and Young's Applied Therapeutics: The Clinical Use of Drugs. 10th ed. Philadelphia, PA: Lippincott William and Wilkins; 2013:1223.

5. Piette JD, Heisler M, Wagner TH. Problems paying out-of-pocket medication costs among older adults with diabetes. Diabetes Care. 2004;27(2):384-391.

6. Rubin RR. Adherence to pharmacologic therapy in patients with type 2 diabetes mellitus. Am J Med. 2005;118(Suppl 5A):27S-34S.

7. Jha AK, Aubert RE, Yao J, Teagarden JR, Epstein RS. Greater adherence to diabetes drugs is linked to less hospital use and could save nearly $\$ 5$ billion annually. Health Aff (Millwood). 2012;31(8):1836-1846.

8. Bangalore S, Kamalakkannan G, Parkar S, Messerli FH. Fixed-dose combinations improve medication compliance: a meta-analysis. Am J Med. 2007;120(8):713-719.

9. Hutchins V, Zhang B, Fleurence RL, Krishnarajah G, Graham J. A systematic review of adherence, treatment satisfaction and costs, in fixed-dose combination regimens in type 2 diabetes. Curr Med Res Opin. 2011;27(6):1157-1168.

10. Prescott J, Manalo B. Considerations for fixed-dose combination productes in cardiometabolic disease. Pharmacy Times [serial on the Internet] [updated December 12, 2011; cited May 15, 2015]. Available from: http://www.pharmacytimes.com/publications/issue/2011/ December2011/Considerations-for-FixedDose-Combination-Productsin-Cardiometabolic-Disease. Accessed February 23, 2015.

11. Truven Health Analytics, Inc. Class Comparison: Antidiabetic Agents. Drug Consults. Micromedex 2.0. Greenwood Village, CO: Truven Health Analytics, Inc.; 2015.
12. FDA approves invokamet. Drugs.com [homepage on the Internet]. [updated August 8, 2014; cited May 15, 2015]. Available from: http:// www.drugs.com/newdrugs/fda-approves-invokamet-canagliflozinmetformin-type-2-diabetes-4068.html. Accessed February 13, 2015.

13. Invokamet [package insert]. Titusville, NJ; Janssen Pharmaceuticals; 2014.

14. Nigro SC, Riche DM, Pheng M, Baker WL. Canagliflozin, a novel SGLT2 inhibitor for treatment of type 2 diabetes. Ann Pharmacother. 2013;47(10):1301-1311.

15. Sha S, Devineni D, Ghosh A, et al. Canagliflozin, a novel inhibitor of sodium glucose co-transporter 2, dose dependently reduces calculated renal threshold for glucose excretion and increases urinary glucose excretion in healthy subjects. Diabetes Obes Metab. 2011;13(7):669-672.

16. Devineni D, Curtin C, Ariyawansa J, et al. Bioequivalence of canagliflozin/metformin immediate release fixed- dose combination tablets compared with concomitant administration of single components of canagliflozin and metformin in healthy fed participants. J Bioequiv Availab. 2014;6:164-173.

17. Stenlöf K, Cefalu WT, Kim KA, et al. Efficacy and safety of canagliflozin monotherapy in subjects with type 2 diabetes mellitus inadequately controlled with diet and exercise. Diabetes Obes Metab. 2013; 15(4):372-382.

18. DeFronzo RA, Goodman AM. Efficacy of metformin in patients with non-insulin-dependent diabetes mellitus. The multicenter metformin study group. $N$ Engl J Med. 1995;333(9):541-549.

19. Cefalu WT, Leiter LA, Yoon KH, et al. Efficacy and safety of canagliflozin versus glimepiride in patients with type 2 diabetes inadequately controlled with metformin (CANTATA-SU): 52 week results from a randomised, double-blind, phase 3 non-inferiority trial. Lancet. 2013;382(9896):941-950.

20. Lavalle-González FJ, Januszewicz A, Davidson J, et al. Efficacy and safety of canagliflozin compared with placebo and sitagliptin in patients with type 2 diabetes on background metformin monotherapy: a randomised trial. Diabetologia. 2013;56(12):2582-2592.

21. American Diabetes Association. Approaches to glycemic treatment. Diabetes Care. 2015;38(Suppl):S41-S48.

22. Qiu R, Capuano G, Meininger G. Efficacy and safety of twice-daily treatment with canagliflozin, A sodium glucose co-transporter 2 inhibitor, added on to metformin monotherapy in patients with type 2 diabetes mellitus. J Clin Trans Endocri. 2014;1:54-60.

23. Jarab AS, Almrayat R, Alqudah S, et al. Predictors of non-adherence to pharmacotherapy in patients with type 2 diabetes. Int J Clin Pharm. 2014;36(4):725-733.

24. Lopez JM, Annunziata K, Bailey RA, Rupnow MF, Morisky DE. Impact of hypoglycemia on patients with type 2 diabetes mellitus and their quality of life, work productivity, and medication adherence. Patient Prefer Adherence. 2014;8:683-692.

25. Schernthaner G, Gross JL, Rosenstock J, et al. Canagliflozin compared with sitagliptin for patients with type 2 diabetes who do not have adequate glycemic control with metformin plus sulfonylurea: a 52-week randomized trial. Diabetes Care. 2013;36(9):2508-2515.

26. Garber AJ, Abrahamson MJ, Barzilay JI, et al. AACE comprehensive diabetes management algorithm 2013. Endocr Pract. 2013;19(2): $327-336$.

Diabetes, Metabolic Syndrome and Obesity: Targets and Therapy

Dovepress

\section{Publish your work in this journal}

Diabetes, Metabolic Syndrome and Obesity: Targets and Therapy is an international, peer-reviewed open-access journal committed to the rapid publication of the latest laboratory and clinical findings in the fields of diabetes, metabolic syndrome and obesity research. Original research, review, case reports, hypothesis formation, expert opinion and commentaries are all considered for publication. The manuscript management system is completely online and includes a very quick and fair peer-review system, which is all easy to use. Visit http://www.dovepress.com/testimonials.php to read real quotes from published authors. 